\title{
Small-Scale landslide Susceptibility Assessment. The Case Study of the Southern Asia ${ }^{+}$
}

\author{
Giacomo Titti ${ }^{1,2, *}$, Lisa Borgatti ${ }^{1,2}$, Qiang Zou ${ }^{3}$ and Alessandro Pasuto ${ }^{2}$ \\ 1 Department of Civil, Chemical, Environmental and Materials Engineering, Alma Mater Studiorum, \\ University of Bologna, 40126 Bologna, Italy; lisa.borgatti@unibo.it \\ 2 Research Institute for Geo-Hydrological Protection, National Research Council of Italy, 35127 Padova, \\ Italy; alessandro.pasuto@irpi.cnr.it \\ 3 Institute of Mountain Hazards and Environment, Chinese Academy of Sciences, Chengdu 610041, China; \\ zouqiang@imde.ac.cn \\ * Correspondence: giacomo.titti@irpi.cnr.it \\ † Presented at TERRAenVISION 2019, Barcelona, Spain, 2-7 September 2019.
}

Published: 11 Novermber 2019

\begin{abstract}
One of the prioritized project of the Belt and Road Initiative is the Silk Road Disaster Risk Reduction. The main aim of the project is to investigate natural hazards affecting Central Asia and Europe in order to understand their evolution and support the spatial planning related to the new infrastructures designing prevention and mitigation measures. The landslide susceptibility zoning is a common practice for land-use planning and environmental impact assessment. Considering the susceptibility as part of the hazard zoning work-flow, a multi-scale (multi-Tier) landslide susceptibility assessment has been carried out and the results are illustrated in this work. Starting from the continental (Tier 1) up to the regional analysis (Tier $\geq 2$ ), the most susceptible areas have been defined to be exploited by successive zoning. Once the most susceptible areas at a regional scale are detected, the hazard zoning can be assessed. In the literature, the landslide susceptibility at continental or global scale has seldom been evaluated. The complexity of the analysis is strictly related to the extension of the study area: the smaller the scale, the higher the complexity of the analysis. Moreover, coordination issues between people and local governments, lack of data due to the absence of strategies for hazards and risk mitigation and data heterogeneity significantly affect the results and forces to find new and innovative solutions from the scientific point of view. In this framework, the Tier 1 landslide susceptibility of the southern Asia has been investigated. It represents the first application of the proposed approach. The results reveal a promising prediction capacity of the method which will be applied to the rest of the Belt and Road study area. The limits, and potentialities of a continental landslide susceptibility are here described. The uncertainty which affect the results of the Tier 1 assessment is mainly related to the lack of consistent data, especially, a global and reliable landslide inventory. However, the Tier 1 landslide susceptibility map has the role to give an overview of the entire study area and to provide the definition of the most landslides prone areas. The method adopted for the analysis is statistically-based and all the resources (software, libraries and data) are open-source. In order to support the reproducibility of the results, a new QGIS tool for statistical analysis has been developed. The Weights of Evidence method has been already implemented, whereas other methods will be coded during further activity.
\end{abstract}

Keywords: landslide susceptibility; multi-scale analysis; Belt and Road Initiative

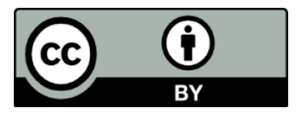

(C) 2019 by the authors. Licensee MDPI, Basel, Switzerland. This article is an open access article distributed under the terms and conditions of the Creative Commons Attribution (CC BY) license (http://creativecommons.org/licenses/by/4.0/). 